\title{
ON THE IMPACT OF PRODUCT REMANUFACTURING AND RECYCLING ON OPERATIONS MANGEMENT
}

\section{M.C. Thierry, M. Salomon, Erasmus Universiteit Rotterdam, NL \\ A.A.N. Ridder, Vrije Universiteit Amsterdam, NL \\ L.N. Van Wassenhove, INSEAD Fontainebleau Cedex, France}

\begin{abstract}
Many organizations are looking into the concepts of remanufacturing and recycling of used products in order to reduce the environmental impact of their business operations, and to make money. The principle of remanufacturing is to manufacture 'as new' products that fulfill predeterminde quality standards. The remanufacturing process involves extensively testing, repair, and removal of used components on all product levels, and the procurement and assembly of new components, when necessary.

Recycling refers to the conversion of used products into their basic materials, which can eventually be reused in the production of new components. This presentation reports on continuing research in product remanufacturing and recycling, and their impact on operations management. It will

(i) contain an overview of the potential advantages and disadvantages of remanufacturing and recycling

(ii) give a brief literature review of remanufacturing, recycling and operations management

(iii) discuss an adaptation of MRP in order to deal with remanufacturing and

(iv) propose some statistical inventory control models that account for remanufacturing and recycling.
\end{abstract}

Keywords:

remanufacturing, recycling, logistics, MRP, statistical inventory control models 